\title{
Dynamic modeling of three-phase upflow fixed-bed reactor including pore diffusion
}

\author{
C. Julcour ${ }^{\mathrm{a}}$, R.V. Chaudhari ${ }^{\mathrm{b}}$, J. M. Le Lann ${ }^{\mathrm{a}}$, A. M. Wilhelmª ${ }^{\mathrm{a}}$ H. Delmas ${ }^{\mathrm{a}, *}$ \\ a Laboratoire de Génie Chimique, CNRS ENSIGC/INPT, 18 Chemin de la Loge, 31078 Toulouse Cedex, France \\ ${ }^{\mathrm{b}}$ Homogeneous Catalysis Division, National Chemical Laboratory, Dr. Homi Bhabha Road, Pune 411 008, India
}

\begin{abstract}
The dynamics of a three-phase upflow fixed-bed reactor are investigated using a non-isothermal heterogeneous model including gas-liquid and liquid-solid mass transfer and diffusion / reaction phenomena inside the catalyst. The partial differential and algebraic equations (PDAE) involving three integration variables (time and two space coordinates) are solved via discretization of the spatial coordinates coupled with the Gear method.

For a multistep hydrogenation on a shell catalyst the model exhibits significant effects of the external and above all internal resistance to hydrogen transfer but also non trivial internal hydrocarbons concentration profiles.

A simplified model is compared to the extended one and to experimental data in transient regime. In the investigated conditions - hydrocarbons in large excess - the diffusion of hydrocarbons appears to be actually not limiting, so that the simplest model predicts accurately the transient reactor behavior.
\end{abstract}

Keywords: fixed-bed reactor, dynamic modeling, internal diffusion, multistep hydrogenation.

\section{INTRODUCTION}

In order to improve the performances of three-phase fixed-bed reactors, several recent papers have studied unsteady-state ways to operate, for instance by imposing periodical variations on the gas or the liquid flow rate (Lange et al. [1] and Gabarain et al. [2]).

For that purpose, models investigating the dynamic behavior of the reactor are useful, as well as to assess the reliability of the model parameters in limit cases (such as hot spot or runaway). However corresponding literature is quite sparse.

Visser et al. [3] and Lange et al. [4] used dynamic models to evaluate conversion and/or selectivity improvements due to forced periodical variations of the gas composition or the liquid flow rate. Wärna et al. [5] simulated the start-up period of fixed-bed reactors in nonisothermal conditions. In a previous article (Julcour et al. [6]) we also examined numerically transient concentration and temperature profiles obtained during the start-up of a co-current upflow reactor or consecutive to flow rate steps.

All those models considered the catalyst pellet as a gradientless volume and did not investigate the effects of internal diffusion on the reactor dynamics.

The objective of this work is to examine in details the transient concentration (and temperature) profiles at the pellet and reactor scale for a reaction highly limited by the diffusion of the gaseous reactant: the hydrogenation of 1,5,9-cyclododecatriene on a $0.5 \%$ $\mathrm{Pd} / \mathrm{Al}_{2} \mathrm{O}_{3}$ shell catalyst. In this model we will consider both the transient diffusion of hydrogen and hydrocarbons inside the pellet (inert support and active layer) and we will investigate their respective roles. The results at the reactor scale will be compared to the predictions of the model developed in the previous article and to experimental measurements obtained with a co-current upflow reactor.

\footnotetext{
*Corresponding author Henri.Delmas@ensigct.fr
} 


\section{EXPERIMENTAL}

\section{INVESTIGATED REACTION}

The partial hydrogenation of cyclododecatriene (CDT) in cyclododecene (CDE) was selected as a complex reaction involving constraints of exothermicity and selectivity.

The cyclododecatriene used in this work was found to contain three isomers: more than 97\% cis,trans,trans-CDT, around $2 \%$ trans,trans,trans-CDT and $0.5 \%$ cis,cis,trans-CDT.

The products of the reaction are respectively: cyclododecadiene (CDD), cyclododecene and cyclododecane (CDA).

A simplified reaction scheme lumping isomers may be written as follows:

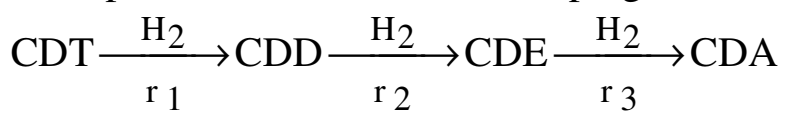

Cylindrical alumina pellets of $3.1 \mathrm{~mm}$ diameter coated with palladium over a depth of 250 $\mu \mathrm{m}$ (Degussa, E263/D, 0.5\% Pd) were used as a catalyst.

The experimental investigation of the kinetics was performed by Stüber et al. [7] and more details can be found in the related paper.

For the intrinsic kinetics (measured with crushed pellets of mean diameter less than $10 \mu \mathrm{m}$ ), an Eley-Rideal model was selected:

$$
\mathrm{R}_{\mathrm{i}}=\frac{\mathrm{k}_{\mathrm{i}} \mathrm{K}_{\mathrm{j}=\mathrm{i}} \mathrm{C}_{\mathrm{j}=\mathrm{i}} \mathrm{C}_{\mathrm{H}_{2}}^{\alpha_{\mathrm{i}}}}{1+\sum_{\mathrm{j}=1}^{3} \mathrm{~K}_{\mathrm{j}} \mathrm{C}_{\mathrm{j}}}
$$

where $\mathrm{i}$ is the reaction number, and $\mathrm{j}$ is the component number $(\mathrm{j}=1$ : CDT, 2: CDD, 3 : CDE).

The Arrhenius and Van't Hoff laws define the rate constants $\mathrm{k}_{\mathrm{i}}$ and adsorption constants $\mathrm{K}_{\mathrm{j}}$ :

$\mathrm{k}_{\mathrm{i}}=\mathrm{k}_{\mathrm{i}, 0} \exp \left(-\mathrm{E}_{\mathrm{i}} / \mathrm{RT}\right)$ and $\mathrm{K}_{\mathrm{j}}=\mathrm{K}_{\mathrm{j}, 0} \exp \left(-\mathrm{A}_{\mathrm{j}} / \mathrm{RT}\right)$.

The corresponding kinetic parameters are given in Julcour et al. [8].

The same type of model was found to be suitable to describe the apparent kinetic law $\mathrm{r}_{\mathrm{i}}^{\prime}$ measured with $3.1 \mathrm{~mm}$ diameter pellets.

The parameters of apparent kinetics are reported in table 1.

\begin{tabular}{|cc|c|c|}
\hline \multicolumn{3}{|c|}{$\mathrm{r}_{\mathrm{i}}^{\prime}=\frac{\mathrm{k}_{\mathrm{i}} \mathrm{K}_{\mathrm{j}=\mathrm{i}} \mathrm{C}_{\mathrm{j}=\mathrm{i}} \mathrm{C}_{\mathrm{H}_{2}}^{\alpha_{\mathrm{i}}}}{1+\mathrm{K}_{\mathrm{CDT}} \mathrm{C}_{\mathrm{CDT}}+\mathrm{K}_{\mathrm{CDD}} \mathrm{C}_{\mathrm{CDD}}+\mathrm{K}_{\mathrm{CDE}} \mathrm{C}_{\mathrm{CDE}}}\left(\mathrm{kmol}^{2} / \mathrm{kg}_{\mathrm{cat}} / \mathrm{s}\right)$} \\
$\begin{array}{c}\text { Frequency factor } \\
\left(\mathrm{kmol}^{1-\alpha} \times \mathrm{m}_{\mathrm{L}}^{3 \alpha} / \mathrm{s} / \mathrm{kg}_{\mathrm{cat}}\right)\end{array}$ & $\begin{array}{c}\text { Activation energy } \\
(\mathrm{kJ} / \mathrm{kmol})\end{array}$ & $\begin{array}{c}\text { Adsorption constant } \\
\left(\mathrm{m}_{\mathrm{L}}{ }^{3} / \mathrm{kmol}\right)\end{array}$ \\
\hline $\mathrm{k}_{1,0}=13.187 \quad \alpha_{1}=1$ & $\mathrm{E}_{1}=34.9 \times 10^{3}$ & $\mathrm{~K}_{\mathrm{CDT}}=100$ \\
\hline $\mathrm{k}_{2,0}=7.016 \quad \alpha_{2}=1$ & $\mathrm{E}_{2}=30.4 \times 10^{3}$ & $\mathrm{~K}_{\mathrm{CDD}}=22.81$ \\
\hline $\mathrm{k}_{3,0}=2.049 \quad \alpha_{3}=1.312$ & $\mathrm{E}_{3}=25.4 \times 10^{3}$ & $\mathrm{~K}_{\mathrm{CDE}}=10.80$ \\
\hline
\end{tabular}


Table 1 - Parameters of apparent kinetics.

\section{FIXED-BED EXPERIMENTS}

The experimental results mentioned below were obtained in a jacketed packed bed reactor $\left(\mathrm{D}_{\mathrm{R}}=0.026 \mathrm{~m}, \mathrm{~L}_{\mathrm{R}}=1.5 \mathrm{~m}\right)$, filled with the $\mathrm{Pd} / \mathrm{Al}_{2} \mathrm{O}_{3}$ pellets and operating in co-current upflow mode.

Pt100 probes located along the reactor provided axial temperature profiles. Liquid samples were also taken at different heights and analyzed by gas chromatography to measure axial concentration profiles.

The complete experimental unit and the start-up procedure were described in a previous paper (Julcour et al. [6]).

Experimental runs were performed at a pressure of 4 bars and at high temperatures (above $433 \mathrm{~K})$. Liquid velocity varied from $3 \times 10^{-4}$ to $10^{-3} \mathrm{~m} / \mathrm{s}$, and gas velocity from 0.03 to 0.12 $\mathrm{m} / \mathrm{s}$ : according to the flow pattern established by Stüber [9] with the same reagents and reactor, those conditions correspond to the pulsing regime. 


\section{DYNAMIC MODELING OF THE THREE-PHASE CATALYTIC UPFLOW REACTOR}

Non-isothermal heterogeneous models were chosen to account for both mass and heat transfer limitations at the gas-liquid and liquid-solid interfaces and the heat exchanges through the reactor walls, including the thermal balance of the cooling fluid.

\section{FUNDAMENTAL ASSUMPTIONS}

The dynamic modeling of the fixed-bed reactor is based on the following assumptions:

1. Radial gradients are negligible: the ratio of reactor diameter $(0.026 \mathrm{~m})$ to reactor length $(1.5 \mathrm{~m})$ is indeed very small, and this hypothesis has been confirmed by radial temperature measurements.

2. Plug flow is assumed for the gas phase, but liquid axial dispersion effects are taken into account.

3. The vaporization of the hydrocarbons is not considered due to their very low vapor pressures (a thermal balance on the whole reactor shows that the heat flux generated by vaporization is less than $5 \%$ of the one produced by the reaction in standard operating conditions). The dissolution enthalpy of hydrogen is totally negligible.

4. Heat transfer to the inner jacket wall is assumed to occur through the liquid phase only. The outer jacket wall is supposed to be perfectly insulated. Walls are assumed to be at a uniform average temperature.

\section{The catalyst wetting is complete.}

6. In the investigated conditions the effective reaction rate is drastically reduced by the diffusion of hydrogen (limiting reagent) inside the catalyst pores. The effectiveness factor, ratio of the actual reaction rate to the intrinsic one (without diffusion limitation), is about $1 \%$. In order to take into account this diffusion limitation, two approaches are proposed:

- the first one (model $I$ ) describes the transient mass balances for each component inside the catalyst pores. Two zones have to be accounted for: the active layer (impregnated with palladium over $250 \mu \mathrm{m}$ ) and the inactive support which can play a significant role as a supply of reagents. This complete model involves three integration variables: a time coordinate $(\mathrm{t})$, a coordinate along the reactor axis $(\mathrm{z})$ and a coordinate along the catalyst radius $(r)$;

- the second one (model II), already examined in a previous article (Julcour et al. [6]), assumes the pellet to be a gradientless volume for the hydrocarbon concentration (CDT, CDD, CDE and CDA). This assumption is fully justified when steady state is reached since the concentration of CDT is very high compared to hydrogen solubility. In the transient regime it supposes that the dynamics of pore diffusion is very fast compared to the evolution of concentrations in the external liquid phase. These considerations allow to simplify the terms describing mass accumulation inside the pellet: a uniform concentration of hydrocarbons and a negligible concentration of hydrogen (thus no accumulation) are assumed. 
In both models the catalyst pellet is supposed to be isothermal and the variations of the amount of reactants adsorbed on the solid phase is neglected.

\section{EQUATIONS OF THE MODEL}

Based on the assumptions described above, the dynamic model is given by the following set of equations:

\section{Mass balances}

Liquid phase (plug flow with axial dispersion)

$\frac{\partial}{\partial t}\left(\varepsilon_{L e x t} C_{L, j}\right)=-\frac{\partial F_{L, j}}{\partial z}+\frac{\partial}{\partial z}\left(\varepsilon_{L e x t} D_{z L i} \frac{\partial C_{L, j}}{\partial z}\right)+\left(N_{G L, j}-N_{L S, j}\right)$

$\mathrm{j}=\mathrm{CDT}, \mathrm{CDD}, \mathrm{CDE}, \mathrm{CDA}, \mathrm{H}_{2}$

with $\quad \mathrm{N}_{\mathrm{GL}, \mathrm{k}}=0 \quad \mathrm{k}=\mathrm{CDT}, \mathrm{CDD}, \mathrm{CDE}, \mathrm{CDA}$ since hydrogen only is present in the gas phase

$$
\begin{aligned}
& N_{G L, H 2}=k_{L} a\left(C_{L, H 2}^{*}-C_{L, H 2}\right) \\
& \text { and } N_{L S, j}=\left(k_{L S} a_{L S}\right)_{j}\left(C_{L, j}-C_{S, j}\right)
\end{aligned}
$$

\section{Catalyst phase}

- Model I takes into account diffusion and reaction phenomena inside the catalyst pores, for both the active layer and the inert support. The catalyst pellet is described as a long cylinder, for which only radial flux are considered (however an equivalent pellet length is estimated to keep the actual active volume $\mathrm{V}_{\mathrm{a}}$ ). Thus model I leads to:

$$
\varepsilon_{\mathrm{p}} \frac{\partial \mathrm{C}_{\mathrm{j}}^{\prime}}{\partial \mathrm{t}}=\mathrm{D}_{\mathrm{e}}\left(\frac{\partial^{2} \mathrm{C}_{\mathrm{j}}{ }_{\mathrm{j}}}{\partial \mathrm{r}^{2}}+\frac{1}{\mathrm{r}} \frac{\partial \mathrm{C}_{\mathrm{j}}^{\prime}}{\partial \mathrm{r}}\right) \quad 0<\mathrm{r}<\mathrm{r}_{\mathrm{p}}-\delta \quad \text { in the inactive part }
$$$$
\varepsilon_{\mathrm{p}} \frac{\partial \mathrm{C}_{\mathrm{j}}}{\partial \mathrm{t}}=\mathrm{D}_{\mathrm{e}}\left(\frac{\partial^{2} \mathrm{C}_{\mathrm{j}}}{\partial \mathrm{r}^{2}}+\frac{1}{\mathrm{r}} \frac{\partial \mathrm{C}_{\mathrm{j}}}{\partial \mathrm{r}}\right)+\sum_{\mathrm{i}} \mathrm{v}_{\mathrm{ij}} \mathrm{R}_{\mathrm{i}} \quad \mathrm{r}_{\mathrm{p}}-\delta<\mathrm{r}<\mathrm{r}_{\mathrm{p}}
$$

$\left(R_{\mathrm{i}}\right.$ is the intrinsic reaction rate per unit volume of active layer)

with the following boundary conditions:

$$
\begin{array}{ll}
\forall t, r=0 & \frac{\partial \mathrm{C}_{\mathrm{j}}{ }_{\mathrm{j}}}{\partial \mathrm{r}}=0 \quad \text { (condition for symmetry) } \\
\forall \forall \mathrm{t}, \mathrm{r}=\mathrm{r}_{\mathrm{p}}-\delta & \left\{\begin{array}{l}
\frac{\partial \mathrm{C}_{\mathrm{j}}}{\partial \mathrm{r}}=\frac{\partial \mathrm{C}_{\mathrm{j}}}{\partial \mathrm{r}} \\
\mathrm{C}_{\mathrm{j}}=\mathrm{C}_{\mathrm{j}}^{\prime}
\end{array}\right.
\end{array}
$$$$
>\forall \mathrm{t}, \mathrm{r}=\left.\mathrm{r}_{\mathrm{p}} \quad \mathrm{C}_{\mathrm{j}}\right|_{\mathrm{r}=\mathrm{r}_{\mathrm{p}}}=\mathrm{C}_{\mathrm{S}, \mathrm{j}}
$$$$
0=N_{L S, j}-\rho_{B} \frac{D_{e_{j}}}{\delta \times \rho_{p}} \times\left.\frac{V_{a}}{V_{p}} \frac{\partial C_{j}}{\partial r}\right|_{r=r_{p}}
$$ 
- Model II neglects the hydrogen amount inside the pellet and assumes a flat concentration profile for hydrocarbons. In order to take into account the effect of internal diffusion in the reaction term, an apparent kinetic law is then used to describe the consecutive hydrogenations ( $r_{i}^{\prime}$ per unit of catalyst weight). This apparent kinetic law has been determined by measurements made with the $3.1 \mathrm{~mm}$ diameter pellets.

$$
\begin{aligned}
& \varepsilon_{\mathrm{p}}(1-\varepsilon) \frac{\partial}{\partial \mathrm{t}}\left(\mathrm{C}_{\mathrm{S}, \mathrm{k}}\right)=\left(\mathrm{N}_{\mathrm{LS}, \mathrm{k}}+\rho_{\mathrm{B}} \sum_{\mathrm{i}} \mathrm{v}_{\mathrm{ik}} \mathrm{r}_{\mathrm{i}}^{\prime}\right) \quad \mathrm{k}=\mathrm{CDT}, \mathrm{CDD}, \mathrm{CDE}, \mathrm{CDA} \\
& 0=\left(\mathrm{N}_{\mathrm{LS}, \mathrm{H} 2}+\rho_{\mathrm{B}} \sum_{\mathrm{i}} v_{\mathrm{iH} 2} \mathrm{r}_{\mathrm{i}}^{\prime}\right)
\end{aligned}
$$

Gas phase (plug flow)

$$
\frac{\partial}{\partial \mathrm{t}}\left(\varepsilon_{\mathrm{Gext}} \mathrm{C}_{\mathrm{G}, \mathrm{H} 2}\right)=-\frac{\partial \mathrm{F}_{\mathrm{G}, \mathrm{H} 2}}{\partial \mathrm{z}}-\mathrm{N}_{\mathrm{GL}, \mathrm{H} 2}
$$

\section{Energy balances}

The heat exchanges through the walls of the jacket are represented in figure 1 .

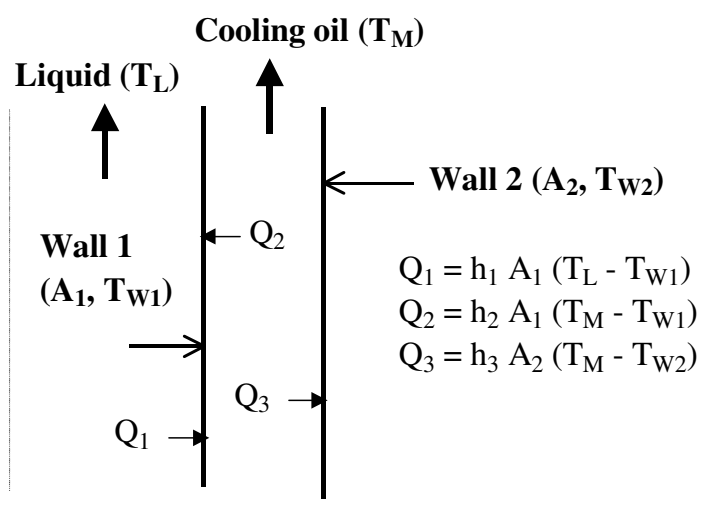

Fig. 1. Schematic drawing of the heat exchanges through the walls of the jacket.

As already mentioned, both dissolution enthalpy of hydrogen and liquid vaporization are ignored in the energy balance equations.

Liquid phase

$$
\begin{aligned}
& \frac{\partial}{\partial t}\left(\varepsilon_{\text {Lext }} \mathrm{H}_{\mathrm{L}}\right)=-\frac{\partial}{\partial \mathrm{z}}\left(\sum_{\mathrm{j}}\left(\mathrm{F}_{\mathrm{L}, \mathrm{j}} \mathrm{H}_{\mathrm{L}, \mathrm{j}}^{\prime}\right)+\frac{\partial}{\partial \mathrm{z}}\left(\Lambda_{\mathrm{zL}} \frac{\partial \mathrm{T}_{\mathrm{L}}}{\partial \mathrm{z}}\right)+\left(\mathrm{h}_{\mathrm{GL}} \mathrm{a}\right)\left(\mathrm{T}_{\mathrm{G}}-\mathrm{T}_{\mathrm{L}}\right)\right. \\
& +\left(\mathrm{h}_{\mathrm{LS}} \mathrm{a}_{\mathrm{LS}}\right)\left(\mathrm{T}_{\mathrm{S}}-\mathrm{T}_{\mathrm{L}}\right)-\frac{\mathrm{h}_{1} \mathrm{~A}_{1}}{\mathrm{~V}_{\mathrm{R}}}\left(\mathrm{T}_{\mathrm{L}}-\mathrm{T}_{\mathrm{W} 1}\right)
\end{aligned}
$$

\section{Catalyst phase}

- Model I: According to stoichiometry:

$$
(1-\varepsilon) \frac{\partial \mathrm{H}_{\mathrm{S}}}{\partial \mathrm{t}}=-\left(\mathrm{h}_{\mathrm{LS}} \mathrm{a}_{\mathrm{LS}}\right)\left(\mathrm{T}_{\mathrm{S}}-\mathrm{T}_{\mathrm{L}}\right)-\rho_{\mathrm{B}} \Delta \mathrm{H}_{\mathrm{R}} \frac{\mathrm{D}_{\mathrm{eH} 2}}{\delta \times \rho_{\mathrm{p}}} \times\left.\frac{\mathrm{V}_{\mathrm{a}}}{\mathrm{V}_{\mathrm{p}}} \frac{\partial \mathrm{C}_{\mathrm{H} 2}}{\partial \mathrm{r}}\right|_{\mathrm{r}=\mathrm{r}_{\mathrm{p}}}
$$

assuming identical heats of reaction for the consecutive hydrogenations $\left(\Delta \mathrm{H}_{\mathrm{R} 1}=\Delta \mathrm{H}_{\mathrm{R} 2}=\Delta \mathrm{H}_{\mathrm{R} 3}=\Delta \mathrm{H}_{\mathrm{R}}\right)$. 
- Model II:

$(1-\varepsilon) \frac{\partial \mathrm{H}_{\mathrm{S}}}{\partial \mathrm{t}}=-\left(\mathrm{h}_{\mathrm{LS}} \mathrm{a}_{\mathrm{LS}}\right)\left(\mathrm{T}_{\mathrm{S}}-\mathrm{T}_{\mathrm{L}}\right)-\left(\rho_{\mathrm{B}} \sum_{\mathrm{i}} \Delta \mathrm{H}_{\mathrm{R}_{\mathrm{i}}} \mathrm{r}_{\mathrm{i}}\right)$

Gas phase (hydrogen only)

$\frac{\partial}{\partial t}\left(\varepsilon_{\mathrm{Gext}} \mathrm{H}_{\mathrm{G}}\right)=-\frac{\partial}{\partial \mathrm{z}}\left(\mathrm{F}_{\mathrm{G}, \mathrm{H} 2} \mathrm{H}_{\mathrm{G}}{ }\right)-\left(\mathrm{h}_{\mathrm{GL}} \mathrm{a}\right)\left(\mathrm{T}_{\mathrm{G}}-\mathrm{T}_{\mathrm{L}}\right)$

Cooling oil (in the jacket)

$\frac{\partial \mathrm{H}_{\mathrm{M}}}{\partial \mathrm{t}}=-\frac{\partial}{\partial \mathrm{z}}\left(\mathrm{F}_{\mathrm{M}} \mathrm{H}_{\mathrm{M}}^{\prime}\right)+\frac{\mathrm{h}_{2} \mathrm{~A}_{1}}{\mathrm{~V}_{\mathrm{an}}}\left(\mathrm{T}_{\mathrm{W} 1}-\mathrm{T}_{\mathrm{M}}\right)-\frac{\mathrm{h}_{3} \mathrm{~A}_{2}}{\mathrm{~V}_{\mathrm{an}}}\left(\mathrm{T}_{\mathrm{M}}-\mathrm{T}_{\mathrm{W} 2}\right)$

Wall 1

$\mathrm{V}_{\mathrm{W} 1} \rho_{\mathrm{st}} \mathrm{C}_{\mathrm{P}, \mathrm{st}}^{\prime} \frac{\partial \mathrm{T}_{\mathrm{W} 1}}{\partial \mathrm{t}}=\mathrm{h}_{1} \mathrm{~A}_{1}\left(\mathrm{~T}_{\mathrm{L}}-\mathrm{T}_{\mathrm{W} 1}\right)-\mathrm{h}_{2} \mathrm{~A}_{1}\left(\mathrm{~T}_{\mathrm{W} 1}-\mathrm{T}_{\mathrm{M}}\right)$

Wall 2

As the external reactor wall is assumed to be perfectly insulated:

$\mathrm{V}_{\mathrm{W} 2} \rho_{\mathrm{st}} \mathrm{C}_{\mathrm{P}, \mathrm{st}}^{\prime} \frac{\partial \mathrm{T}_{\mathrm{W} 2}}{\partial \mathrm{t}}=\mathrm{h}_{3} \mathrm{~A}_{2}\left(\mathrm{~T}_{\mathrm{M}}-\mathrm{T}_{\mathrm{W} 2}\right)$

Pressure drop

The pressure drop is supposed to be negligible:

$\mathrm{P}-\mathrm{P}_{\text {inlet }}=0$

Description of liquid holdup and enthalpies

In order to lighten the equations structure and to make easier the introduction of new correlations, liquid holdup and enthalpies are treated as independent variables respecting the following algebraic equations:

$\varepsilon_{\text {Lext }}-m \varepsilon_{\text {Lext }}=0 \quad$ with $m \varepsilon_{\text {Lext }}$ the model for the external liquid holdup (13)

Note that liquid hold-up variations (mainly due to the gas flow rate) are not considered here, and the overall liquid flow rate is assumed to remain constant during the stepwise changes of the gas flow rate

$\mathrm{H}_{\mathrm{L}}-m \mathrm{H}_{\mathrm{L}}=0 \quad m \mathrm{H}_{\mathrm{L}}=\int_{\text {Tref }}^{\mathrm{TL}} \rho_{\mathrm{L}} \mathrm{C}_{\mathrm{P}, \mathrm{L}}^{\prime}(\mathrm{T}) \mathrm{dT}$

(Where an average specific heat for the liquid is used, as no significant differences exist between the specific heats of the organic reactants)

$\mathrm{H}_{\mathrm{S}}-m \mathrm{H}_{\mathrm{S}}=0$

For the catalyst phase enthalpy calculation, both the enthalpy of the solid and the enthalpy of the liquid contained in the pores are considered: 


$$
\begin{aligned}
& m \mathrm{H}_{\mathrm{S}}=\int_{\text {Tref }}^{\mathrm{TS}}\left(\rho_{\mathrm{p}} \mathrm{C}_{\mathrm{P}, \mathrm{p}}^{\prime}(\mathrm{T})+\varepsilon_{\mathrm{p}} \rho_{\mathrm{Lp}} \mathrm{C}_{\mathrm{P}, \mathrm{Lp}}^{\prime}(\mathrm{T})\right) \mathrm{dT} \\
& \mathrm{H}_{\mathrm{G}}-m \mathrm{H}_{\mathrm{G}}=0 \quad m \mathrm{H}_{\mathrm{G}}=\mathrm{C}_{\mathrm{G}, \mathrm{H} 2} \int_{\text {Tref }}^{\mathrm{TG}} \mathrm{C}_{\mathrm{P}, \mathrm{G}}{ }_{\mathrm{H} 2}(\mathrm{~T}) \mathrm{dT}
\end{aligned}
$$

(Since the liquid vapor pressure ( 0.16 bar at $433 \mathrm{~K})$ is negligible compared to the gas pressure (4 bars), vaporized liquid reactants can be neglected in the gas enthalpy).

$$
\begin{aligned}
& \mathrm{H}_{\mathrm{M}}-m \mathrm{H}_{\mathrm{M}}=0 \quad m \mathrm{H}_{\mathrm{M}}=\int_{\text {Tref }}^{\mathrm{TM}} \rho_{\mathrm{M} \mathrm{C}_{\mathrm{P}, \mathrm{M}}^{\prime}}(\mathrm{T}) \mathrm{dT} \\
& \mathrm{C}_{\mathrm{G}, \mathrm{H} 2}-\frac{\rho_{\mathrm{G}, \mathrm{H} 2}}{\mathrm{M}_{\mathrm{H} 2}}=0
\end{aligned}
$$

\section{$\underline{\text { Initial and boundary conditions }}$}

\section{Initial conditions}

The liquid phase contains CDT saturated with $\mathrm{H}_{2}$. The concentrations on the catalyst surface equal the concentrations in the liquid phase. The catalyst pores are filled with CDT.

The hydrogen flow rate is uniform along the reactor.

The temperatures of the gas, liquid and catalyst phases are all equal to the inlet temperature of the gas-liquid mixture (low temperature to prevent any reaction prior to $t=0$ ).

Time $t=0$ corresponds to the pre-heated cooling oil entering the reactor jacket, which starts the reaction.

\section{Boundary conditions}

For the liquid phase, Danckwerts' conditions are used:

at $\mathrm{z}=0$ and $\forall \mathrm{t}$

$$
\begin{aligned}
& \varepsilon_{\mathrm{Lext}} \mathrm{D}_{\mathrm{zLi}} \frac{\partial \mathrm{C}_{\mathrm{L}, \mathrm{j}}}{\partial \mathrm{z}}=\left(\mathrm{F}_{\mathrm{L}, \mathrm{j}}\right)_{\mathrm{z}=0}-\left(\mathrm{F}_{\mathrm{L}, \mathrm{j}}\right)_{\text {inlet }} \\
& \mathrm{j}=\mathrm{CDT}, \mathrm{CDD}, \mathrm{CDE}, \mathrm{CDA}, \mathrm{H}_{2}
\end{aligned}
$$

$$
\left(\frac{\Lambda_{\mathrm{zL}}}{\rho_{\mathrm{L}} \mathrm{C}_{\mathrm{P}, \mathrm{L}}^{\prime} \mathrm{u}_{\mathrm{L}}}\right) \frac{\partial \mathrm{T}_{\mathrm{L}}}{\partial \mathrm{z}}=\left(\mathrm{T}_{\mathrm{L}}\right)_{\mathrm{z}=0}-\left(\mathrm{T}_{\mathrm{L}}\right)_{\text {inlet }}
$$

at $\mathrm{z}=\mathrm{L}_{\mathrm{R}}$ and $\forall \mathrm{t}$

$$
\frac{\partial \mathrm{C}_{\mathrm{L}, \mathrm{j}}}{\partial \mathrm{z}}=0 \quad \text { (21) } \quad \frac{\partial \mathrm{T}_{\mathrm{L}}}{\partial \mathrm{z}}=0
$$

\section{MODEL PARAMETERS}

Except kinetic data, models involve more than ten parameters to be determined from the literature or by specific experiments.

The effective diffusivity $D_{e j}$ is obtained from the molecular diffusivity by: $D_{e_{j}}=\frac{\varepsilon}{\tau} D_{m_{j}}$ with $\varepsilon$ the porosity $(\varepsilon=0.45)$ and $\tau$ the tortuosity factor $(\tau=7.2)$ of the catalyst particles. 
$\mathrm{D}_{\mathrm{mj}}$ is calculated from the correlation of Diaz et al. [10] for hydrogen and from the correlation of Wilke and Chang (cf. Reid et al. [11]) for CDT and its derivatives. The tortuosity factor has been estimated by comparing initial consumption rates of hydrogen measured with $3.1 \mathrm{~mm}$ diameter pellets and crushed particles and assuming a first order reaction kinetics.

For the calculation of the liquid holdup $\varepsilon_{\text {Lext }}$, the gas-liquid mass transfer coefficient $\mathrm{k}_{\mathrm{L}} \mathrm{a}$, the liquid-solid mass transfer coefficient of hydrogen $\left(\mathrm{k}_{\mathrm{LS}}\right)_{\mathrm{H} 2}$, and the wall heat transfer coefficient $\mathrm{h}_{1}$, empirical relations have been established using the same reaction and reactor system (Stüber [9]): they depend above all on the gas flow rate.

The correlation of Specchia et al. [12] is used to calculate the liquid-solid mass transfer coefficients of hydrocarbons. Models are found not to be sensitive to this parameter in its usual range, so that its accuracy is not very important.

Axial dispersion is estimated from Stüber [9].

The axial thermal conductivity is deduced from the analogy between mass and heat transfer: $\mathrm{Pe}_{\mathrm{mL}}=\mathrm{Pe}_{\mathrm{tL}}$. In fact this analogy underestimates the axial conductivity, as the solid contributes directly to heat conduction but indirectly to dispersion.

For the gas-liquid heat transfer, a high coefficient has been used, based on the assumption that the temperatures of both gas and liquid phases are the same.

In the absence of reliable relations for the upflow reactor, the liquid-solid heat transfer coefficient is deduced from the well known Kunii and Levenspiel equation derived in single phase fixed beds:

$$
\mathrm{Nu}=2+1.8 \operatorname{Re}_{\mathrm{p}}{ }^{1 / 2} \operatorname{Pr}^{1 / 3}
$$

The heat transfer coefficient is then probably underestimated, nevertheless calculated heat effects remain very low.

Preliminary simulations made with a steady state model derived from model II have put into evidence that three of the parameters mentioned above have a great influence on the concentration and temperature axial profiles:

- gas-liquid and the liquid-solid mass transfer coefficients of hydrogen (concentration profiles),

- wall heat transfer coefficient (temperature profile).

The sensitivity of the predictions to these parameters is reported in the following table.

\begin{tabular}{|l|c|c|}
\hline \multicolumn{1}{|c|}{ Parameter } & Concentration profiles & Temperature profile \\
\hline $\mathrm{k}_{\mathrm{L}} \mathrm{a}$ & +++++ & ++++ \\
\hline$\left(\mathrm{k}_{\mathrm{LS}}\right)_{\mathrm{H} 2}$ & ++++ & +++ \\
\hline$\left(\mathrm{k}_{\mathrm{LS}}\right)_{\mathrm{hydrocarbons}}$ & - & - \\
\hline $\mathrm{h}_{1}$ & ++ & +++++ \\
\hline
\end{tabular}

Table 2 - Sensitivity of the concentration and temperature profiles on several parameters.

Experimental steady state profiles have been used to adjust the sensitive parameters: slight corrections (less than 25\%) were needed to fit the experimental data. 


\section{NUMERICAL TREATMENT}

\section{REDUCTION OF THE PDAE SYSTEMS}

Model I and II lead to a set of partial differential and algebraic equations (PDAE).

In order to keep a system structure close to the original one (to make easier future developments), the set of equations was reduced by the method of lines: the PDAE were converted to DAE by discretization of the spatial derivatives (z-derivatives and also $r$ derivatives for model I) with finite differences. Then the resultant DAE systems were solved by the software package DISCo (Sargousse et al. [13] and Le Lann [14]).

Model II was first tested for the plug flow mode by comparing its predictions when steady state conditions are reached with the results of a steady state model where spatial derivatives are integrated by the Gear method.

From a number of spatial divisions equal to 10 , model II was checked to give the same axial concentration profiles as the steady state model.

However in order to describe more precisely the axial temperature profile (which is relatively steep close to the reactor inlet), 40 divisions were used to discretize the reactor.

At the pellet scale (model I), the mesh size was chosen to make coincide one of the discretization points and the interface between the inert support and the active layer. The catalyst pellet was then parted in 31 elements. The last element adjacent to the liquid-solid interface was itself parted into 50 divisions for a more accurate calculation of the mass flux.

\section{TREATMENT OF THE RESULTANT DAE SYSTEMS (DISCo)}

According to the reduction method and the number of discretization points chosen, the resultant system associated to model II involves nearly 1000 differential and algebraic equations (while model I leads to more than 16000 equations).

So the corresponding dynamic operators exhibit a banded structure with a high void degree. The DAE solver applied here - DISCo - has been developed from a modified version of the LSODI package based on the Gear method (Hindmarsh [15]). It has been improved in robustness and reliability in order to solve problems typically encountered in the chemical engineering field, characterised by rapid transient phenomena, stiffness, large scale systems, high non linearity, external and intrinsic discontinuities.

More particularly this software allows different treatments of the jacobian matrix to increase storage and calculation efficiency: full, banded or sparse mode. For instance, in the case of model II, twice less computation time is needed when sparse mode is used instead of banded mode. A fortiori sparse treatment was applied to model I, allowing the program to simulate 200 minutes of operation during the reactor start-up in about 25 minutes CPU ${ }^{1}$.

\footnotetext{
${ }^{1}$ IBM RS6000, 390, $66 \mathrm{MHz}$
} 


\section{RESULTS AND DISCUSSION}

\section{START-UP OF THE REACTOR}

Models were first applied to describe the start-up of the fixed-bed reactor for various flow rate conditions. Transient axial temperature and concentration profiles were compared with the experimental values.

\section{Concentration profiles at the pellet scale}

Along the reactor axis, model I gives transient concentration profiles in all the different phases, especially in the catalyst pores. Figure 2 exhibits hydrogen and CDT concentration profiles at the reactor outlet, one hour after the reaction has begun.

The figure puts into evidence the existence of great resistance at the gas-liquid and liquidsolid interfaces (hydrogen concentration at the catalyst surface is less than $10 \%$ of hydrogen solubility). This phenomenon is all the more marked since gas flow rate, then $\mathrm{k}_{\mathrm{L}} \mathrm{a}$ is low. It is also shown that the internal resistance in the catalyst pores is even more significant, as hydrogen concentration falls steeply to zero in the pellet.

After one hour of operation, the concentration of CDT is higher at the pellet center than at its surface, revealing a slow diffusion of the hydrocarbon from the inert support (initially filled with CDT) to the reaction zone at the catalyst surface.

When steady state is reached (inside the external liquid phase and the catalyst pores), CDT concentration profile in the pellet is nearly flat as expected, since the concentration of CDT is very high compared to hydrogen solubility.

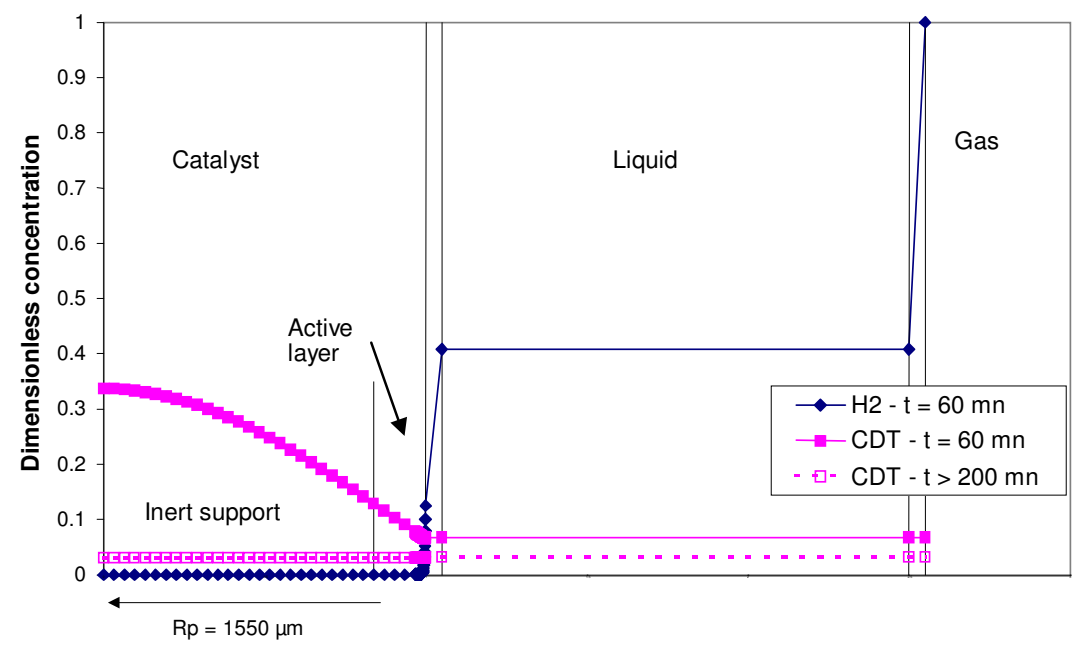

Fig. 2. Dimensionless concentration profiles at the reactor outlet.

(defined either as the ratio of the hydrogen concentration to the solubility or the ratio of the CDT concentration to the sum of the hydrocarbon concentrations).

\section{Concentration and temperature profiles at the reactor scale}

Figures 3 and 4 illustrate two examples of axial concentration profiles calculated by models I and II at different times during the start-up of the reactor.

Before steady state conditions the observed differences between the predictions of the two models can be explained by their distinct description of the pellet dynamics:

- model I introduces a slow diffusion of the non-volatile components inside the catalyst pores (so that pores are still filled with CDT, whereas a high amount of this reagent has already been consumed in the liquid bulk), 


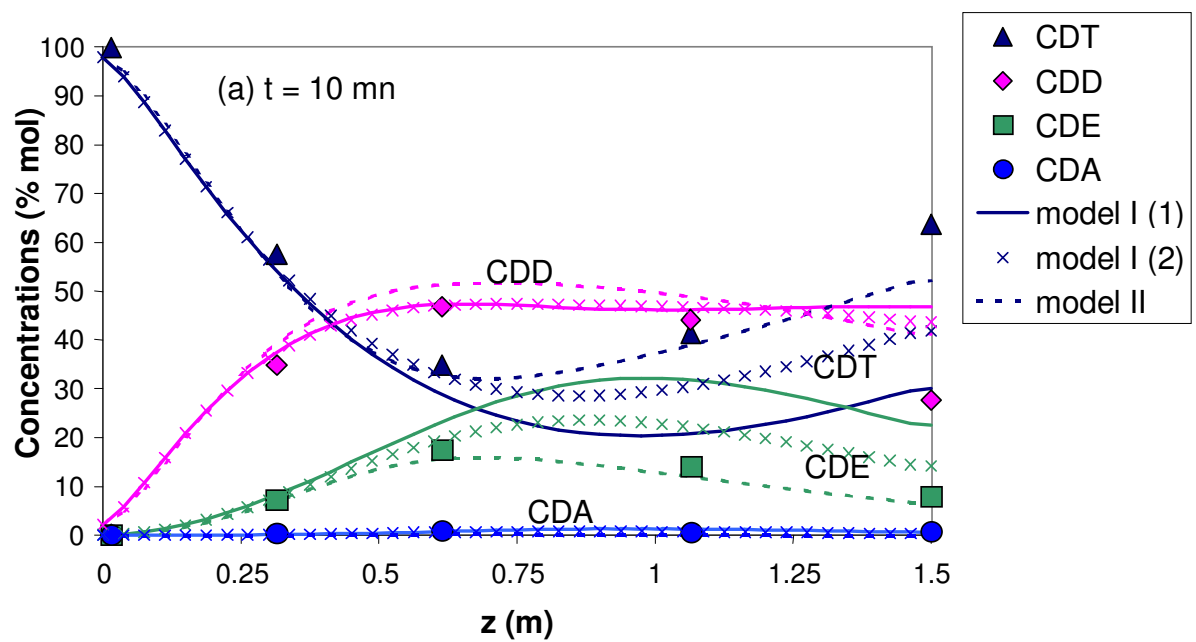

(1) model parameters unchanged

(2) effective diffusivities of hydrocarbons multiplied by a factor 5
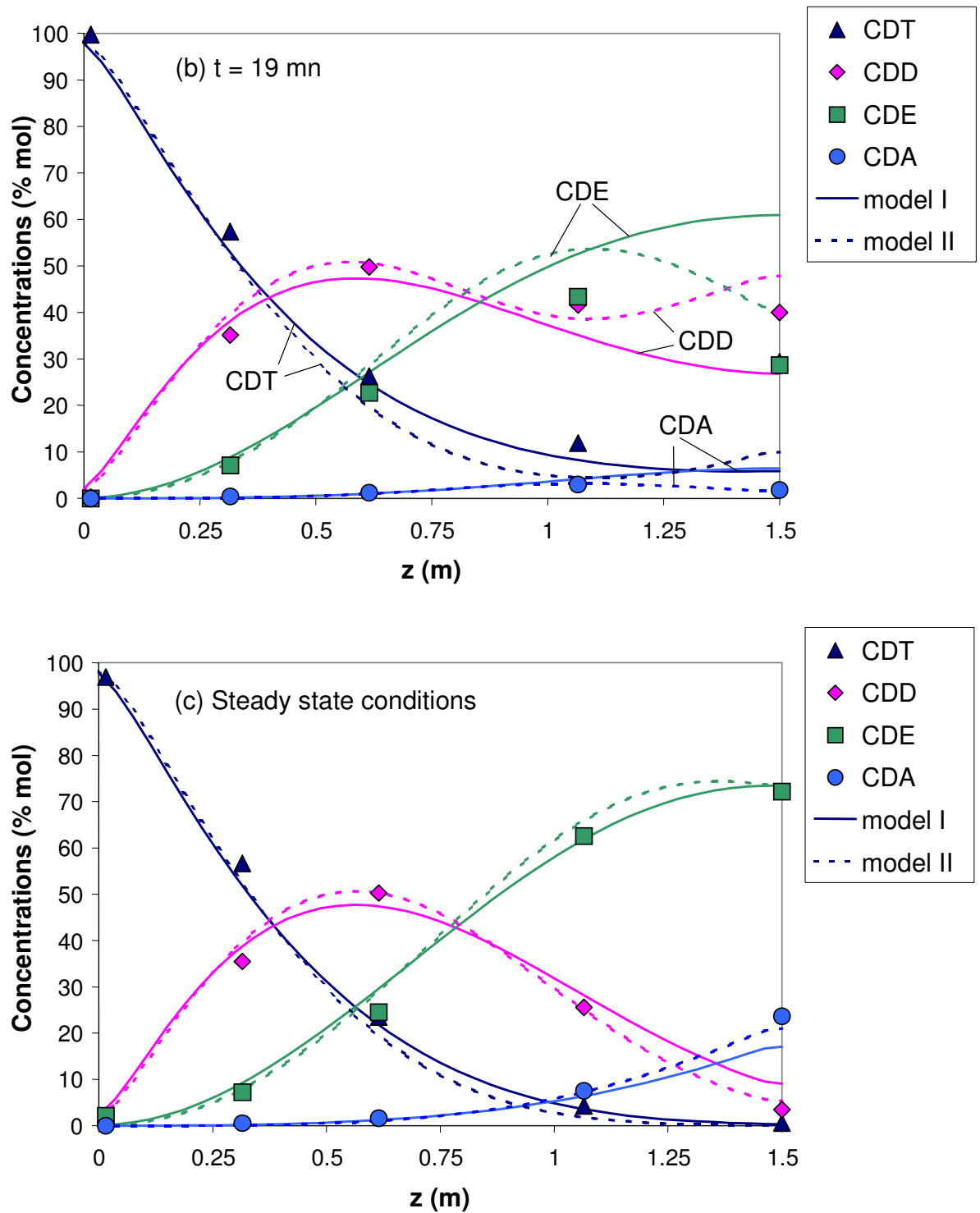

Fig. 3 - Concentration profiles during the start-up.

$\mathrm{P}=4$ bars, $\mathrm{T}_{\text {inlet }}=313 \mathrm{~K}, \mathrm{u}_{\mathrm{L}, \text { inlet }}=0.52 \times 10^{-3} \mathrm{~m} / \mathrm{s}, \mathrm{u}_{\mathrm{G} \text {,inlet }}=0.050 \mathrm{~m} / \mathrm{s}, \mathrm{T}_{\mathrm{M}, \text { inlet }}=150^{\circ} \mathrm{C}$. 

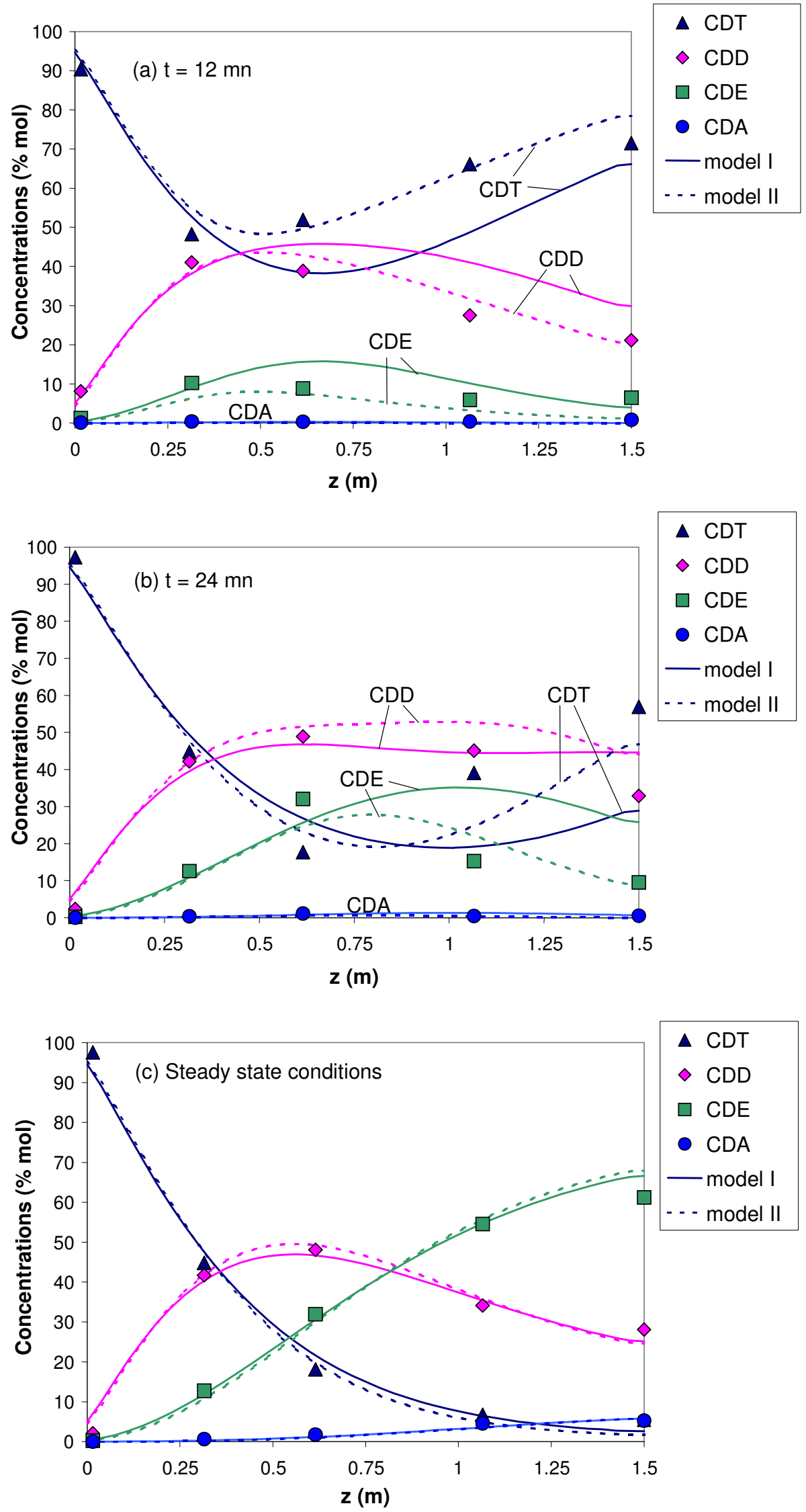

Fig. 4 - Concentration profiles during the start-up.

$\mathrm{P}=4$ bars, $\mathrm{T}_{\text {inlet }}=323 \mathrm{~K}, \mathrm{u}_{\mathrm{L}, \text { inlet }}=0.34 \times 10^{-3} \mathrm{~m} / \mathrm{s}, \mathrm{u}_{\mathrm{G}, \text { inlet }}=0.027 \mathrm{~m} / \mathrm{s}, \mathrm{T}_{\mathrm{M} \text {,inlet }}=150^{\circ} \mathrm{C}$. 
- model II assumes that, at any time, hydrocarbon concentrations in the catalyst pores equal bulk concentrations.

That is why smaller differences are observed (figure 3a) if effective diffusivities of hydrocarbons are multiplied by a factor 5 (this multiplying factor would largely compensate for a probable overestimation of the tortuosity factor).

When steady state conditions are reached (figure $3 \mathrm{c}$ and $4 \mathrm{c}$ ), results are - as expected similar whatever the applied model - intrinsic kinetics coupled with internal diffusion (model I) or apparent kinetic law (model II).

When model predictions are compared to experimental measurements, it appears that actually the diffusion time of hydrocarbons should be fast compared to the bulk concentration evolution. It must be mentioned that model I underestimates diffusion efficiency as only radial flux are taken into account in the pellet model. Moreover the real nature of the active layer (homogeneity of the catalytic deposit, depth, tortuosity factor) should be more complex than described in model I. This may explain why model II predictions are surprisingly in a better agreement with the experimental data.

Simulations also exhibit a minimum for the concentration of CDT, which was experimentally checked. This minimum moves towards the top of the reactor when time increases and disappears when steady state conditions are reached (cf. figures $3 \mathrm{c}$ and $4 \mathrm{c}$ ).

This phenomenon results from the complex coupling between hydrodynamics and initial conditions (at $\mathrm{t}=0$ the column is full of cyclododecatriene saturated with hydrogen at a low temperature): the liquid phase leaving the reactor during the transient regime has only reacted on a fraction of the bed height and moreover with a reduced hydrogen gas flow (leading to a lower external mass transfer). Figure 5 shows that the axial concentration profile of hydrogen in the liquid phase forms rapidly (in less that 10 minutes, order of magnitude of the time needed to get steady temperatures), imposing a decreasing profile of reaction rate. It results in an increasing concentration of CDT towards the top of the reactor, as long as the liquid has not been renewed by the convective flux.

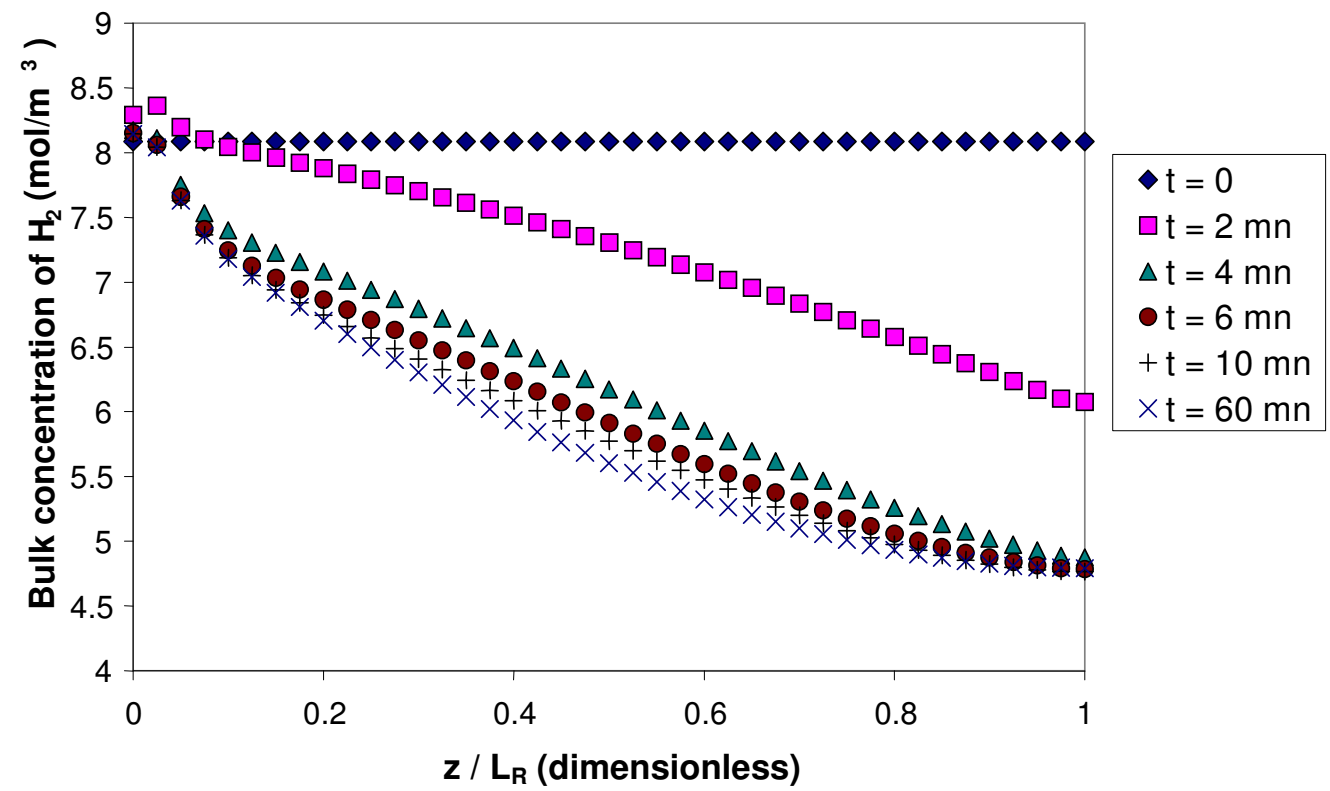

Fig. 5 - Axial concentration profile of hydrogen in the liquid phase during the start-up. $\mathrm{P}=4$ bars, $\mathrm{T}_{\text {inlet }}=323 \mathrm{~K}, \mathrm{u}_{\mathrm{L}, \text { inlet }}=0.4 \times 10^{-3} \mathrm{~m} / \mathrm{s}, \mathrm{u}_{\mathrm{G} \text {,inlet }}=0.027 \mathrm{~m} / \mathrm{s}, \mathrm{T}_{\mathrm{M} \text {,inlet }}=150^{\circ} \mathrm{C}$. 
A typical axial temperature profile in steady state conditions is given in figure 6: it exhibits a maximum near the reactor inlet, due to the heat flux generated by the exothermic reaction (at its maximum near the inlet) and to the high heat transfer at the reactor wall.

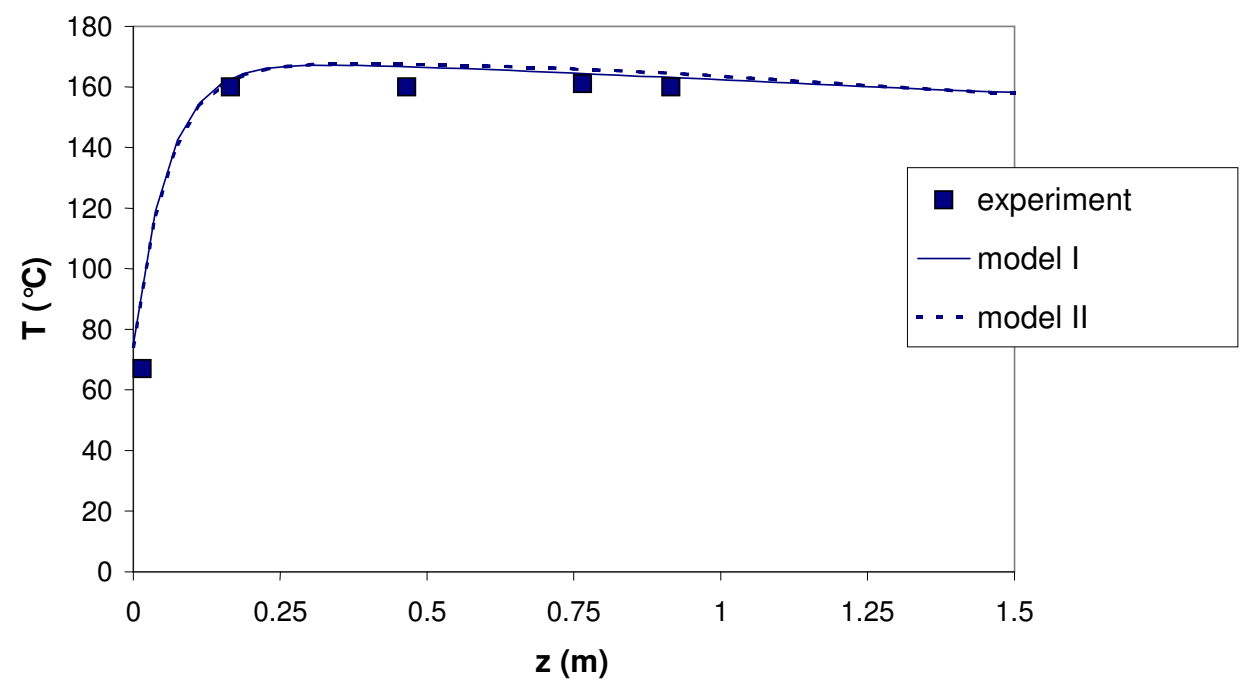

Fig. 6 - Axial temperature profile in steady state conditions.

$\mathrm{P}=4$ bars, $\mathrm{T}_{\text {inlet }}=313 \mathrm{~K}, \mathrm{u}_{\mathrm{L}, \text { inlet }}=0.52 \times 10^{-3} \mathrm{~m} / \mathrm{s}, \mathrm{u}_{\mathrm{G} \text {,inlet }}=0.050 \mathrm{~m} / \mathrm{s}, \mathrm{T}_{\mathrm{M} \text {,inlet }}=150^{\circ} \mathrm{C}$.

\section{RESPONSE TO A CHANGE IN OPERATING CONDITIONS}

In order to investigate further the reliability of the dynamic model II, it was used to predict the influence of a step change in the gas or liquid flow rate.

For that purpose techniques for discontinuity treatment were applied, such as the use of a cubic polynomial function to simulate the valve opening (or closing).

Stepwise changes of the flow rates (up to $100 \%$ ) were imposed to the reactor and the predicted time-concentration curves were compared to experimental responses.

Figures 7 and 8 give typical responses of the system to such a sudden increase in the gas flow rate. The numerical results fit well the observed transient behavior: it is seen that the conversion increases to reach the second steady state profile after a period of 25 minutes, representing nearly twice the estimated residence time.

Indeed a rise of the gas velocity increases the reaction rate by accelerating gas-liquid and liquid-solid mass transfer (figure 7). Moreover it goes with a less efficient heat dissipation, as the wall heat transfer coefficient is a decreasing function of gas velocity in pulse flow regime, leading to an increase of overall reactor temperature (figure 8). This latter figure reveals also that thermal dynamics is significantly faster than concentration evolution. 


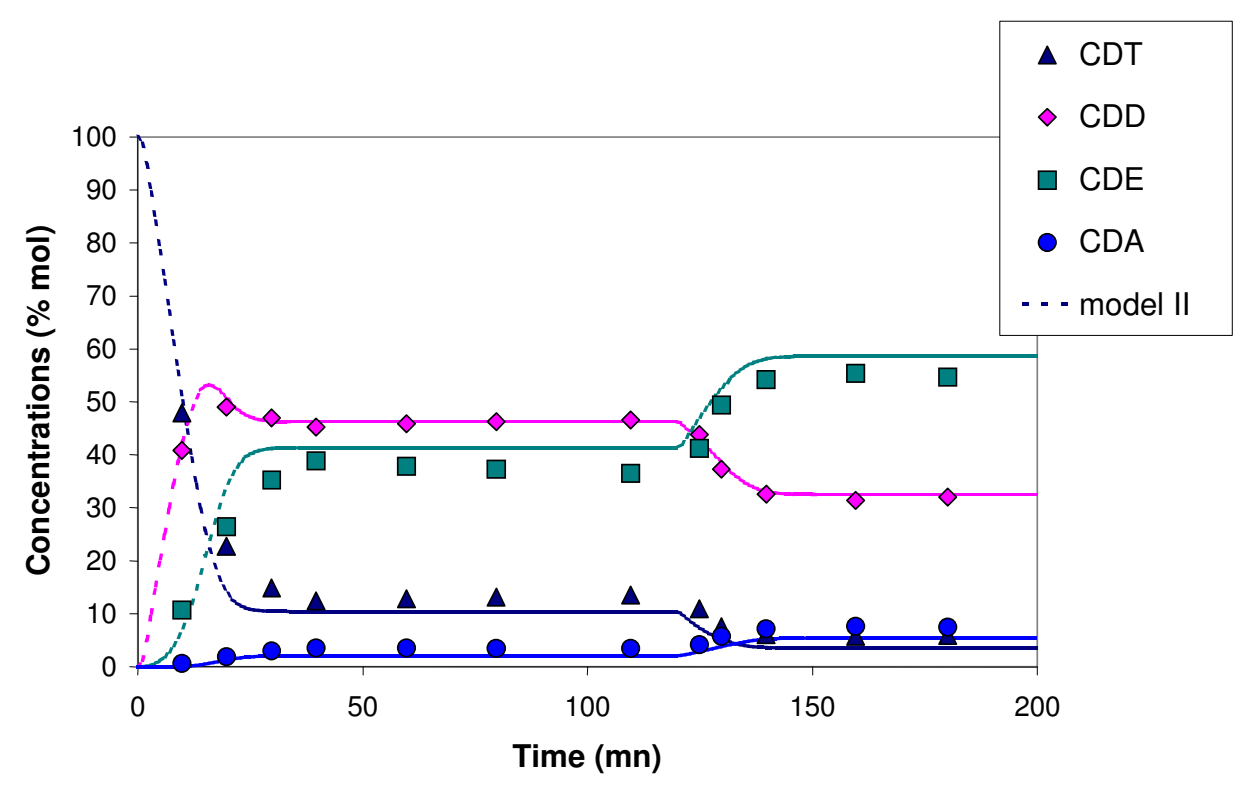

Fig. 7 - Concentration evolution at $Z=1.065 \mathrm{~m}$ when increasing $\mathrm{u}_{\mathrm{G} \text {,inlet }}$ from 0.04 to $0.06 \mathrm{~m} / \mathrm{s}$ at $\mathrm{t}=120 \min \left(\mathrm{u}_{\mathrm{L}, \text { inlet }}=0.55 \times 10^{-3} \mathrm{~m} / \mathrm{s}, \mathrm{P}=4\right.$ bars, $\left.\mathrm{T}_{\mathrm{M} \text {,inlet }}=150^{\circ} \mathrm{C}\right)$.

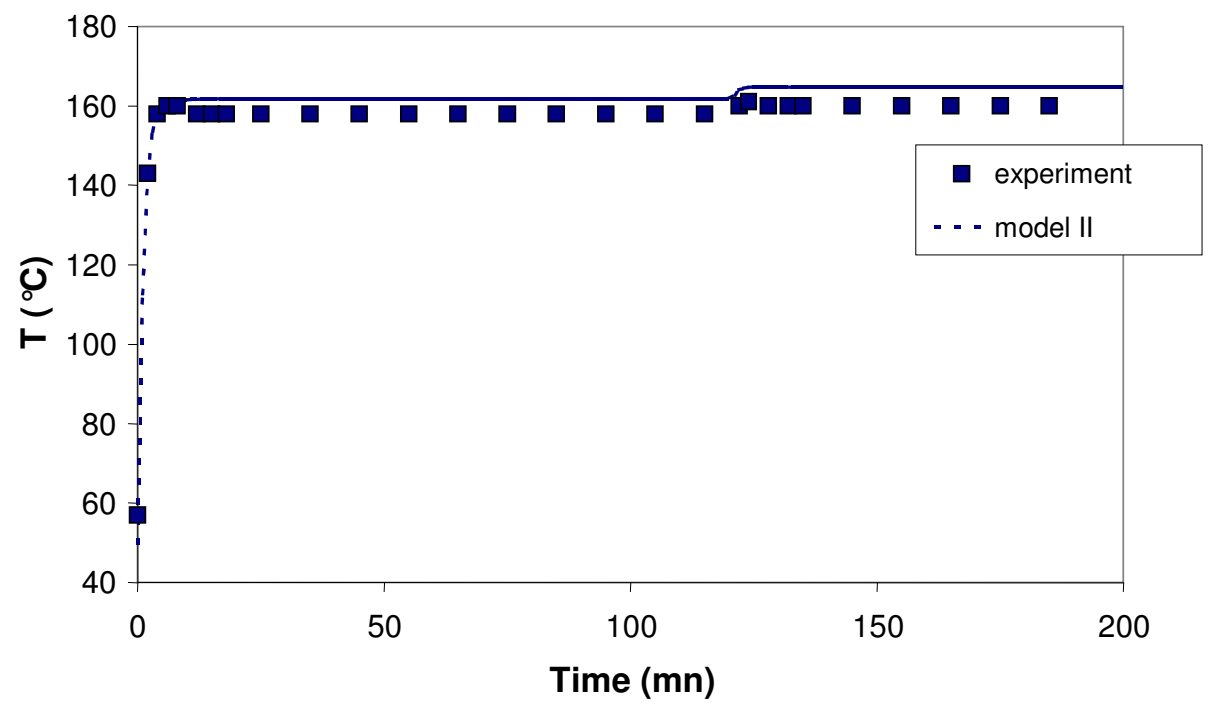

Fig. 8 - Temperature evolution at $\mathrm{Z}=0.915 \mathrm{~m}$ when increasing $\mathrm{u}_{\mathrm{G} \text {,inlet }}$ from 0.04 to $0.06 \mathrm{~m} / \mathrm{s}$ at $\mathrm{t}=120 \mathrm{~min}\left(\mathrm{u}_{\mathrm{L}, \text { inlet }}=0.55 \times 10^{-3} \mathrm{~m} / \mathrm{s}, \mathrm{P}=4\right.$ bars, $\left.\mathrm{T}_{\mathrm{M} \text {,inlet }}=150^{\circ} \mathrm{C}\right)$. 


\section{CONCLUSION}

In this paper two ways of describing the phenomena at the pellet scale for the dynamic modeling of a three-phase fixed-bed reactor were compared: a detailed one coupling intrinsic kinetics with internal diffusion and a simplified one assuming flat hydrocarbon concentration profiles inside the catalyst pores and using an apparent kinetic law.

The resulting PDAE systems were solved by using both discretization techniques and a DAE solver based on the Gear method (DISCo): this numerical treatment proved to be reliable and quite efficient (the simplest model needs less than one minute $\mathrm{CPU}^{1}$ to simulate 200 minutes of operation including a flow rate change).

The models were assessed for the hydrogenation of 1,5,9-cyclododecatriene on $\mathrm{Pd} / \mathrm{Al}_{2} \mathrm{O}_{3}$ by comparing their results to experimental measurements performed in an upflow reactor.

The extended model put into evidence the role of hydrocarbon diffusion on the whole reactor dynamics, as well as the effect of external and internal resistance to hydrogen transfer on the observed reaction rate.

However in the investigated conditions, this extended model does not improve the prediction of the reactor transient behavior, as the hydrocarbon diffusion is not limiting. Its description of pore diffusion appears to need still improvement, by accounting for the real pellet geometry and maybe also including transient adsorption phenomena.

Nevertheless such a sophisticated model is useful to better understand how the dynamics of the whole reactor is influenced by the transient phenomena at different scales, and specially for reactions much more sensitive to hydrocarbon concentrations - remember a quasi zero order is observed here. Moreover thanks to improved numerical techniques and computer tools it does not require much CPU time.

In case of non limiting hydrocarbon diffusion, the simplified model proved its reliability to describe the start-up of the reaction as well as the response to a gas or liquid flow rate variation in standard working conditions. It can be then regarded as a first step to the optimization of the reactor performances in the transient regime.

\section{Acknowledgments}

The authors would wish to thank IFCPAR (Indo-French Center for the Promotion of Advanced Research) for the financial support of this work. 


\section{NOTATION}

a

$\mathrm{a}_{\mathrm{LS}}$

$\mathrm{A}_{1}$

$\mathrm{A}_{2}$

$\mathrm{C}$

$\mathrm{C}_{\mathrm{L}, \mathrm{H} 2}^{*}$

$\mathrm{C}_{\mathrm{P}}$

$\mathrm{C}_{\mathrm{P}}^{\prime}$

$\mathrm{D}_{\mathrm{e}}$

$d_{p}$

$1_{p}$

$D_{R}$

$\mathrm{D}_{\mathrm{zLi}}$

F

$\mathrm{H}$

$\mathrm{H}^{\prime}$

$\mathrm{h}_{\mathrm{GL}}$

$\mathrm{h}_{\mathrm{LS}}$

$\mathrm{h}_{1}$

$\mathrm{h}_{2}$

$\mathrm{h}_{3}$

$\mathrm{k}_{\mathrm{L}} \mathrm{a}$

$\mathrm{k}_{\mathrm{LS}}$

$\mathrm{L}_{\mathrm{R}}$

$\mathrm{Nu}$

$\mathrm{Pe}_{\mathrm{mL}}$

$\mathrm{Pe}_{\mathrm{tL}}$

Pr

$r$

$\mathrm{Re}_{\mathrm{p}}$

$\mathrm{R}_{\mathrm{i}}$

$r_{i}^{\prime}$

$\mathrm{r}_{\mathrm{p}}$

$\mathrm{T}$

$\mathrm{t}$

u

$\mathrm{V}_{\mathrm{a}}$

$\mathrm{V}_{\text {an }}$

$\mathrm{V}_{\mathrm{p}}$

$\mathrm{V}_{\mathrm{R}}$

$\mathrm{V}_{\mathrm{W} 1}$

$\mathrm{V}_{\mathrm{W} 2}$

$\mathrm{Z}$

$=$ gas-liquid interfacial area per unit reactor volume, $\mathrm{m}^{2} / \mathrm{m}^{3}$

$=$ liquid-solid interfacial area per unit reactor volume, $\mathrm{m}^{2} / \mathrm{m}^{3}$

$=$ inner wall reactor surface $($ wall 1$), \mathrm{m}^{2}$

$=$ outer wall reactor surface (wall 2), $\mathrm{m}^{2}$

$=$ concentration, $\mathrm{mol} / \mathrm{m}^{3}$

$=$ dissolved hydrogen concentration at the gas-liquid interface, $\mathrm{mol} / \mathrm{m}^{3}$

$=$ specific heat, $\mathrm{J} / \mathrm{mol} / \mathrm{K}$

$=$ specific heat, $\mathrm{J} / \mathrm{kg} / \mathrm{K}$

$=$ effective pore diffusivity, $\mathrm{m}^{2} / \mathrm{s}$

$=$ pellet diameter, $\mathrm{m}$

$=$ pellet length, $\mathrm{m}$

$=$ reactor inner diameter, $\mathrm{m}$

= axial dispersion coefficient based on interstitial velocity, $\mathrm{m}^{2} / \mathrm{s}$

= molar flow rate per unit surface area, $\mathrm{mol} / \mathrm{m}^{2} / \mathrm{s}$

= enthalpy per unit volume of the phase considered, $\mathrm{J} / \mathrm{m}^{3}$

$=$ molar enthalpy, $\mathrm{J} / \mathrm{mol}$

= gas to liquid heat transfer coefficient, $\mathrm{W} / \mathrm{m}^{2} / \mathrm{K}$

= liquid to solid heat transfer coefficient, $\mathrm{W} / \mathrm{m}^{2} / \mathrm{K}$

= bed to wall 1 heat transfer coefficient, $\mathrm{W} / \mathrm{m}^{2} / \mathrm{K}$

= wall 1 to cooling oil heat transfer coefficient, $\mathrm{W} / \mathrm{m}^{2} / \mathrm{K}$

= cooling oil to wall 2 heat transfer coefficient, $\mathrm{W} / \mathrm{m}^{2} / \mathrm{K}$

$=$ gas-liquid volumetric mass transfer coefficient, $\mathrm{s}^{-1}$

$=$ liquid-solid mass transfer coefficient, $\mathrm{m} / \mathrm{s}$

$=$ reactor length, $\mathrm{m}$

$=$ particle Nusselt number

$=$ liquid phase mass Peclet number $\left(=\mathrm{u}_{\mathrm{L}} \mathrm{L}_{\mathrm{R}} /\left(\varepsilon_{\mathrm{Lext}} \mathrm{D}_{\mathrm{zL} \mathrm{i}}\right)\right)$

$=$ liquid phase thermal Peclet number $\left(=\mathrm{u}_{\mathrm{L}} \rho_{\mathrm{L}} \mathrm{C}_{\mathrm{P}, \mathrm{L}}^{\prime} \mathrm{L}_{\mathrm{R}} / \Lambda_{\mathrm{zL}}\right)$

$=$ liquid phase Prandtl number

$=$ distance from the pellet axis, $\mathrm{m}$

$=$ particle Reynolds number (for liquid phase)

$=$ intrinsic reaction rate per unit active layer volume, $\mathrm{mol} / \mathrm{s} / \mathrm{kg}$

$=$ apparent reaction rate per unit catalyst weight, $\mathrm{mol} / \mathrm{s} / \mathrm{kg}$

$=$ pellet radius, $\mathrm{m}$

$=$ temperature, $\mathrm{K}$

$=$ time, $\mathrm{s}$

$=$ superficial velocity, $\mathrm{m} / \mathrm{s}$

$=$ volume of the active layer of a pellet, $\mathrm{m}^{3}$

$$
\mathrm{V}_{\mathrm{a}}=\pi \times\left(\mathrm{l}_{\mathrm{p}}-2 \delta\right) \times \delta \times\left(\mathrm{d}_{\mathrm{p}}-\delta\right)+2 \times \frac{\pi \mathrm{d}_{\mathrm{p}}^{4}}{4} \times \delta
$$

$=$ annular volume between jacket walls, $\mathrm{m}^{3}$

$=$ volume of a pellet, $\mathrm{m}^{3}$

$$
\mathrm{V}_{\mathrm{p}}=\frac{\pi \mathrm{d}_{\mathrm{p}}^{4}}{4} \times \mathrm{l}_{\mathrm{p}}
$$

$=$ reactor inner volume, $\mathrm{m}^{3}$

$=$ volume of wall $1, \mathrm{~m}^{3}$

$=$ volume of wall $2, \mathrm{~m}^{3}$

$=$ spatial coordinate along the reactor axis, $\mathrm{m}$ 

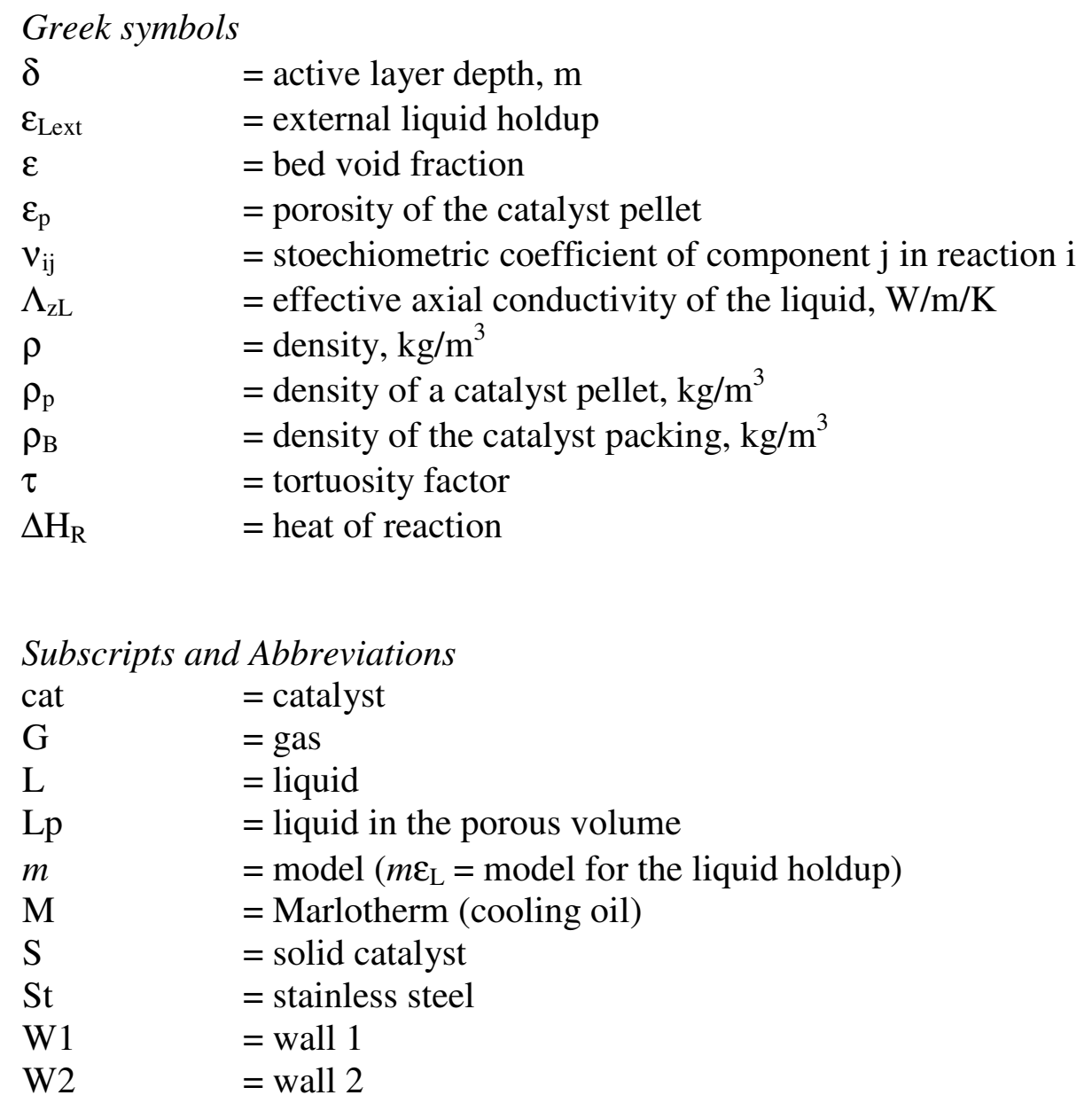

\section{REFERENCES}

[1] Lange, R., Hanika, J., Stradiotto, D., Hudgins R.R. and Silveston, P.L. (1994) Investigations of periodically operated trickle-bed reactors. Chem. Eng. Sc., 49, 56155621.

[2] Gabarain, L., Castellari, A. T., Cechini, J., Tobolski, A. and Haure, P. (1997) Analysis of rate enhancement in a periodically operated trickle-bed reactor. AIChE J., 43 (1), 166-172.

[3] Visser, J. B. M., Stankiewicz, A., Van Dierendonck, L. L., Manna, L., Sicardi, S. and Baldi, G. (1994) Dynamic operation of a three-phase upflow reactor for the hydrogenation of phenylacetylene. Catalysis Today 20, 485-500.

[4] Lange, R., Gutsche, R., Hanika, J. (1999) Forced periodic operation of a trickle bed reactor. Chem. Eng. Sc., 54, 2569-2573.

[5] Wärna, J. and Salmi, T. (1996) Dynamic modelling of catalytic three phase reactors. Comput. Chem. Eng. 20 (1), 39-47.

[6] Julcour, C., Stüber, F., Le Lann, J.M., Wilhelm, A.M. and Delmas, H. (1999) Dynamics of a three-phase upflow fixed-bed catalytic reactor. Chem. Eng. Sc., 54, 2391-2400.

[7] Stüber, F., Benaissa, M. and Delmas, H. (1995) Partial hydrogenation of 1,5,9cyclododecatriene in three phase catalytic reactors. Catalysis Today, 24, 95-101.

[8] Julcour, C., Le Lann, J.M., Wilhelm A.M., and Delmas H. (1999) Dynamics of internal diffusion during the hydrogenation of 1,5,9-cyclododecatriene on $\mathrm{Pd} / \mathrm{Al}_{2} \mathrm{O}_{3}$. Catalysis Today, 48 (1-4), 147-159. 
[9] Stüber, F. (1995) Sélectivité en réacteur catalytique triphasique : analyse expérimentale et théorique d'hydrogénations consécutives en lit fixe catalytique à co-courant ascendant de gaz et de liquide. Ph. D. thesis. Institut National Polytechnique de Toulouse, ENSIGC, France.

[10] Diaz, M., Vega A. and Coca J. (1987) Correlation for the estimation of gas-liquid diffusivity. Chem. Eng. Commun., 52, 271-287.

[11] Reid, R.C., Prausnitz, J.M. and Pauling, B.E. (1987) The properties of gases and liquids. $4^{\text {th }}$ Edition, Mc Graw Hill, New York.

[12] Specchia, V., Baldi, G. and Gianetto, A. (1978) Solid-liquid mass transfer in concurrent two-phase flow through packed beds. Ind. Eng. Chem. Process. Des. Dev. 17 (3), 362-367.

[13] Sargousse, A., Le Lann, J. M., Joulia, X. and Jourda, L. (1999) DISCo : Un nouvel environnement de simulation orienté - objet. MOSIM'99 (6-8 octobre 1999, Annecy), 6166 (SCS International).

[14] Le Lann, J.M. (1996) Internal Report, User Manual, LGC Toulouse, France.

[15] Hindmarsh A.C. (1980) LSODE and LSODI, two initial value ordinary differential equation solvers. ACM SIGNUM Newsletter 15 (4), 10-11. 